\title{
Fasting Therapy - an Expert Panel Update of the 2002 Consensus Guidelines
}

\author{
Françoise Wilhelmi de Toledo ${ }^{a}$ Andreas Buchinger ${ }^{b}$ Hilmar Burggrabe ${ }^{c}$ Gunter Hölz \\ Christian Kuhn $^{a}$ Eva Lischka ${ }^{a}$ Norbert Lischka ${ }^{a}$ Hellmut Lützner ${ }^{d}$ Wolfgang May \\ Martha Ritzmann-Widderich ${ }^{f}$ Rainer Stange ${ }^{g} \quad$ Anna Wessel $^{\mathrm{h}} \quad$ Michael Boschmann $^{\mathrm{i}}$ \\ Elisabeth Peper ${ }^{\mathrm{a}}$ Andreas Michalsen ${ }^{\mathrm{g}, \mathrm{j}}$
}

${ }^{a}$ Klinik Buchinger Wilhelmi, Überlingen,

${ }^{\mathrm{b}}$ Klinik Dr. Otto Buchinger, Bad Pyrmont,

${ }^{c}$ Berufsverband Fasten- und Ernährung, Stuttgart,

${ }^{\mathrm{d}}$ Kurpark-Klinik, Überlingen,

${ }^{e}$ Hufeland Klinik, Bad Mergentheim,

f Praxis Ritzmann-Widderich, Rottweil,

${ }^{g}$ Immanuel-Krankenhaus Berlin, Abteilung für Naturheilkunde,

${ }^{\text {h }}$ Praxis Wessel-Duddeck,

' Charité - Universitätsmedizin Berlin, Franz-Volhard-Centrum für Klinische Forschung am Experimental and Clinical

Research Center (ECRC),

j Charité - Universitätsmedizin Berlin, Institut für Sozialmedizin, Epidemiologie und Gesundheitsökonomie, Berlin, Deutschland

\section{Keywords \\ Fasting · Guidelines · Consensus · Fasting Therapy}

\section{Summary}

Fasting for medical purpose (fasting therapy) has a long tradition in Europe and is established as a defined therapeutic approach in specialized fasting hospitals or within clinical departments for integrative medicine. In 2002, the first guidelines for fasting therapy were published following an expert consensus conference; here we present a revised update elaborated by an expert panel. Historical aspects and definitions, indications, methods, forms, and accompanying procedures of fasting as well as safety and quality criteria of fasting interventions are described. Fasting has shown beneficial effects in various chronic diseases with highest level of evidence for rheumatic diseases. Preliminary clinical and observational data and recently revealed mechanisms of fasting and caloric restriction indicate beneficial effects of fasting also in other chronic conditions such as metabolic diseases, pain syndromes, hypertension, chronic inflammatory diseases, atopic diseases, and psychosomatic disorders. Fasting can also be applied for preventing diseases in healthy subjects. In order to guarantee successful use of fasting and to ensure adherence of all safety and quality standards it is mandatory that all interventions during fasting are guided/accompanied by physicians/therapists trained and certified in fasting therapy.

\section{Schlüsselwörter \\ Fasten · Richtlinien · Konsens · Fastentherapie}

\section{Zusammenfassung}

Medizinisches Fasten (Fastentherapie) hat eine lange Tradition in Europa und ist als klar definierter therapeutischer Ansatz in speziellen Fastenkliniken oder in klinischen Abteilungen für integrative Medizin etabliert. Im Jahr 2002 wurden in Folge einer Experten-Konsensus-Konferenz erstmals Richtlinien zur Fastentherapie veröffentlich; hier präsentieren wir die von einer Expertengruppe überarbeitete und aktualisierte Fassung. Historische Aspekte und Definitionen, Indikationen, Methoden, Formen und entsprechende Verfahren des Fastens sowie Sicherheits- und Qualitätskriterien von Fasten-Behandlungen werden beschrieben. Fasten hat positive Effekte bei verschiedenen chronischen Krankheiten gezeigt, mit dem höchsten Evidenzgrad insbesondere bei rheumatischen Erkrankungen. Erste klinische und Beobachtungsdaten sowie kürzlich erkannte Mechanismen des Fastens und der kalorischen Restriktion zeigen auch für andere chronische Erkrankungen positive Wirkungen des Fastens, darunter Stoffwechselerkrankungen, Schmerzsyndrome, Bluthochdruck, chronische Entzündungserkrankungen, atopische Erkrankungen und psychosomatische Störungen. Fasten kann auch zur Prävention von Krankheiten bei Gesunden angewendet werden. Um den erfolgreichen Einsatz des Fastens und die Einhaltung aller Sicherheits- und Qualitätsstandards zu gewährleisten, ist es zwingend erforderlich, dass alle Eingriffe während des Fastens von Ärzten/Therapeuten betreut werden, die für die Fastentherapie zertifiziert sind.

\section{KARGER \\ Fax +497614520714 \\ Information@Karger.com}

www.karger.com (c) 2013 S. Karger GmbH, Freiburg

$1661-4119 / 13 / 0206-0434 \$ 38.00 / 0$

Accessible online at:

www.karger.com/fok
Françoise Wilhelmi de Toledo, M.D.

Klinik Buchinger Wilhelmi

Wilhelm-Beck-Straße. 27, 88662 Überlingen, Germany 


\section{Introduction}

Seasonal fluctuations in food supply influenced eating behavior and energy metabolism of all living beings over the course of evolution. The ability to accumulate and store energy, essentially in adipose tissues, in order to survive food shortage, has allowed humans and animals to live on earth. In periods of diminished sun exposure and food availability, animals and humans developed specific fasting strategies to cope with calorie restriction. Fasting is thus the ability to meet the body's requirements for macro- and micronutrients during a limited period of either shortage or absence of food, by making use of the body's energy reserves, without endangering health [1].

Physiologically, decreasing requirements as well as substrate and energy-sparing mechanisms, for instance the switch from glucose to fat oxidation in important body tissues, especially in the central nervous system, allow the body to spare protein and maintain organ and cellular function on the long run. During fasting, the energy normally needed for digestion, resorption, transport, and storage of nutrients, is saved. The cell switches to a protected mode, where the aging pathways are deactivated [4]: the genes expressed are those activating repair enzymes. Healthy cells turn into a multiple resistance state [47], whereas cancer cells are weakened by the lack of glucose, proteins, and IGF-1. Fasting as biological necessity has evolved into voluntary fasting traditions with specific ethno-cultural modifications. It was further developed either in religious/spiritual contexts or for medical therapeutic purposes [48,51]. In Germany, there is a long tradition of naturopathy (Naturheilkunde) with key therapeutic features centering on health-promoting lifestyle, specific nutritional therapies, and fasting. Two important schools of fasting have emerged in German speaking countries: 1. The fasting cure (Heilfasten) developed by Otto Buchinger [2] and the medical fasting cure according to Franz-Xaver Mayr [3].

Buchinger and his followers developed a multidisciplinary and multimodal treatment concept for inpatients, centered on fasting therapy, in which physiotherapy, nutrition, mind-body methods, and psychotherapy as well as physical activity are combined within a complex health education program [5]. Aspects of the religious fasting tradition have remained fundamental components within the concept: the dimension of mindfulness and social group support.

The first guidelines on fasting therapy were developed in a consensus conference of experts in 2002 [6]. The present paper gives a revised expert panel update of the original 2002 guidelines. The panel's goal was the description of the therapeutic procedure and of standards fostering the postgraduate education of physicians, the establishment of quality criteria to assure best clinical practice, and the stimulation of scientific research on the issues of fasting. The expert guidelines and the present update should help physicians, medical experts, and patients to use an established fasting method and to ensure best quality. The method which is described in this paper can also be useful for people who fast for religious or spiritual purpose.
In Germany, fasting is taught in the frame of postgraduate educational curricula since 1978 . The self-experience of fasting has been traditionally a part of this education. Since 1996, the Medical Association for Fasting and Nutrition (Ärztegesellschaft für Heilfasten und Ernährung, ÄGHE) grants a certificate of training in fasting therapy for physicians complying with certain criteria. Since 1986, a nonmedical 'fasting guide' education is offered by some institutions. Fasting guides and physicians are encouraged to cooperate with each other.

\section{Definition of Fasting and Various Forms of Fasting}

Fasting is the voluntary abstinence from solid food and stimulants (caffeine, nicotine) for a limited period of time. When fasting is done properly, one should experience a good level of vitality and absence of hunger. The process of fasting involves the person in all its dimensions: body, soul, and spirit. During the fasting period, one should

- take up at least 2.5 1/day of calorie-free liquid (water, herbal tea) as well as vegetable broth, fruit or vegetable juices, and honey, maximum 1,500-2,100 kJ (approximately $250-500 \mathrm{kcal} /$ day)

- promote the stimulation of excretory systems: intestines, liver, kidneys, lungs, and skin

- maintain a good balance between exercise and rest.

For successful fasting, a mindful and stepwise reintroduction of solid food intake is of importance and a cornerstone to successfully adopt a more healthy lifestyle following fasting. The human organism has the physiological ability to switch from exogenous food supply to endogenous nutrient reserves. Fasting triggers cardiovascular, metabolic, and psychological changes which should be monitored during the fasting period [7].

Water-only fasting and several types of modified fasting regimens display some differences, although all are about partial or total interruption of food intake for a limited period of time. They are often mixed up, and the term fasting is sometimes used also for weight-loss diets, e.g., very low calorie diet with an energy intake of up to $600-800 \mathrm{kcal} /$ day.

\subsection{Therapeutic Fasting (According to Buchinger)}

Buchinger (1878-1966) called therapeutic fasting 'Heilfasten' (healing fasting, fasting cure). It consisted of a medically supervised, inpatient multidisciplinary fasting regimen [8] with 3 dimensions (medical, psychosocial, spiritual) that can be used for prevention, 'fasting for the healthy' or as therapy (see chapter 5). Traditionally, Buchinger fasting is based on daily intake of vegetable broth $(1 / 4)$, fruit or vegetable juices $(1 / 4 \mathrm{l})$, and honey $(30 \mathrm{~g})$ as well as 2-2.5 1 of fluid intake by herbal teas and water [9]. The intake of buttermilk (according to Fahrner) [5] is allowed for longer fasting periods (see chapter 4: Methods). 
In addition to the physical dimension (medical physiological therapeutic effects), a psychosocial dimension emerges mediated by group support and group dynamics when people are fasting together. The spiritual dimension characterized by the promotion of spiritual practice and eventually improved access to higher levels of consciousness - an aim of all world religions can be an important experience and feature of fasting [10]. These 3 dimensions show synergistic effects and should not be separated from each other. Buchinger further emphasized the importance of 'dietetics of the soul' during fasting, such as reading, music, viewing paintings, nature, humor, and meditation [11] as well as restriction of media, news, and daily life stress.

\subsection{Fasting for the Healthy}

This term refers to a shorter period of nonmedical fasting which can also be monitored by a fasting guide [12]. The ÄGHE recommends that a physician with fasting experience should be additionally available for background supervision (see chapter 5: Fasting for the Healthy).

\subsection{Different Forms of Fasting}

A) Classification according to the state of health

Therapeutic fasting (fasting cure)

Preventive fasting

Fasting for the healthy (without therapeutic or medical intention).

B) Classification according to the type of supervision (see also chapter 4.4: Quality Control)

I Inpatient with supervision by physician: hospitals, clinics

II Outpatient with supervision by physician: local physicians III No supervision by physician but by fasting guides.

\subsection{Methods Similar to Fasting}

\section{F. X. Mayr Therapy}

Mayr (1875-1965), an Austrian physician, developed a regimen of fasting and calorie restriction in 3 steps: The first step consists of tea and water-only fasting, the second step of a hypocaloric milk-bread diet, and the third one of a 'mild intestinal diet, poor in fibers'. Characteristics of Mayr's therapy are a specific physician-based diagnosis of gastrointestinal disturbances and a manual abdominal massage [13].

\section{Schroth Cure}

Johann Schroth (1798-1856), an Austrian naturopath, developed a calorie-restricted vegetarian diet rich in carbohydrates. Days with restricted fluid intake alternate with days of abundant drinking. During these days, also the intake of up to
$500 \mathrm{ml}$ white wine is allowed. The boosting of excretory systems is also part of the treatment, especially through enhancement of perspiration by damp-heat packs [14].

\section{Whey Cure}

This fasting procedure is supplemented with whey, a proteinrich milk product [15]; alternatively oatmeal or buckwheat gruel can also be given as supplement. For all these forms of fasting, the nutritional energy intake should not exceed $500 \mathrm{kcal} /$ day.

\section{Intermittent Fasting}

Two of the first physicians, who propagated health advantages from any type of cyclic caloric restriction, respectively intermittent fasting, were Edward Hooker Dewey (1837-1904) who favored every day fasting until late noon in the late 19th century in USA; and the French physician Guillaume Guelpa (1850-1930) who practiced continuing cycles of fasting for 2-5 days, followed by vegetarian food for 12-15 days, early in the 20th century. As a result of abundant experimental research on calorie restriction in the recent years, some methods of alternate or intermittent fasting have been established and translated into human clinical research and medical practice. Most commonly, alternate day fasting (AFD, every-other-day diet) or schedules with fixed combinations (e.g., 5 eating / 2 fasting days or 25 eating / 5 fasting days) are currently used [16,17]. Intermittent and alternate fasting consist of interchanging days; eating days when subjects may consume food ad libitum, and fasting days when food is restricted or withheld fully. Intermittent fasting can be done on a regular daily life base. Some of the main postulated beneficial effects of therapeutic fasting are displayed by intermittent fasting. Preliminary findings postulate a reduced risk of type 2 diabetes and cardiovascular disease as well as potential beneficial effects in cancer treatment, yet more research is required.

\subsection{Weight Reduction Methods Which Should Be Distinguished from Fasting}

\section{Zero Calorie Diet}

The zero calorie diet is defined as total calorie restriction and interruption of food intake for weeks or months with the primary goal of weight reduction in cases of massive overweight [18]. Zero calorie diets were first performed in a medically supervised inpatient setting. Disadvantages of zero diets are the protein catabolism and the lack of multidimensional supportive methods. In consequence, relapses and weight regain were frequent, costs were high, and safety critical. It is no longer practiced since the 1970s.

\section{Protein-Modified Formula Diets (Very Low Calorie Diet or $V L C D)$}

These are macro- and micronutrient drinks having a high content in protein. They are subject to manufacturing guidelines regulated by law and are available without prescription for pur- 
poses of weight reduction. VLCD programs are conducted on an outpatient basis $[19,20]$. VLCDs lead to weight reduction but often lack the other dimension of support and have little impact on lifestyle modification and nutritional adherence.

\subsection{Situations Which Display Some Physiological Similarities with Fasting but Are Decidedly Different}

\section{Starvation}

Although metabolic processes during starvation [22] and during fasting share some common features, psychophysiological processes show significant differences. Starvation is normally a forced, mentally stressful, and chronic condition, whereas fasting is voluntary, limited in duration, and usually practiced by people in adequate nutritional state.

Furthermore, the psychosocial condition of starving and fasting people differs fundamentally: Starvation is usually accompanied with situations of misery, poverty, natural disasters, wars, and other stressful situations. As such, it is commonly associated with fear and trauma.

The psychological condition has not only impact on physical well-being but also on physiological functions during fasting, e.g., protein metabolism and the turn-over of some micronutrients are accelerated by stress. During a voluntary well-performed fasting, the increased central availability of the neurotransmitter serotonin, brain-derived neurotrophic factor (BDNF), and endogenous opioids may also generate mood enhancement and states of euphoria [23, 24].

\section{Anorexia Nervosa}

Anorexia nervosa is a frequent psychosomatic eating disorder, occurring mostly in young women. It is characterized by immoderate food restriction and irrational fear of gaining weight as well as a distorted body self-perception. This specific form of self-imposed starvation can lead to serious organ damage and death. Of note, those known and perhaps still unknown neuroendocrine changes and reward mechanisms that occur during fasting might also contribute to the endogenous psychological reinforcement of otherwise dysfunctional behavior, as can be observed in anorexia nervosa.

\section{Hunger Strike}

Hunger strike is the voluntary abstinence from food as a political expression of protest. It is often an act of desperation in which the possibility of a fatal outcome is reckoned with. The physical-medical dimension is ignored by the striking person for obvious reasons.

\subsection{Periodic Interruption of Food Intake in Animals}

'Fasting' in animals is guided by instinct or is the result of geobiological conditions. It serves to survive in times when no food is available and to cope with winter. It is mentioned here due to the abundance of scientific literature on the topic, and serves as a model to understand resources and physiological processes in fasting. Fasting in animals varies according to the species: Some birds fast in order to stay with their brood during incubation to protect it from natural predators. Migratory birds fast during migration while engaging in intensive physical activity. Other animals reduce their energy consumption by entering lethargic states (hibernation) [25, 26]. King penguins fast - in the Antarctic cold - for extremely long periods and can lay their eggs and molt while fasting [27].

\section{Indications}

Fasting therapy is an interdisciplinary form of treatment because it intervenes in a multitude of metabolic and physiologic regulatory systems and thus affects many different organ systems as well as the psychological state and the mood; it further changes the genes expression.

Fasting has empirically documented beneficial effects on

- metabolic syndrome and diseases

- chronic inflammatory diseases

- chronic cardiovascular diseases

- chronic pain syndromes

- atopic diseases

- psychosomatic disorders.

For treatment of rheumatoid arthritis there is level 1 evidence by a systematic review of randomized trials [28, 29]. There is preliminary evidence from smaller nonrandomized controlled trials or observational studies for metabolic syndrome [30-34, 50], osteoarthritis [35], fibromyalgia [36], hypertension [37-39], chronic pain syndromes of the locomotor system [23, 40], migraine [41], enhancement of lifestyle change $[42,8]$ and psychological well-being, support of chemotherapy $[43,44]$, and mood-enhancement $[23,45]$.

Fasting therapy requires active collaboration of the subject. A better response in patients having a strong desire to fast has been documented [29]. In addition, the degree of experience of the physician specialized in fasting may play a decisive role in the indication and success of fasting for a specific patient and the monitoring of the fasting course.

The fasting program and fasting duration have to be tailored individually, based on the indication and individual constitutional aspects. Also, the patient has to be sensitized in order to enhance motivation and active participation during the course of fasting. The spectrum of indications and the nosologic understanding of diseases and distinct complaints may be different and broader within a more holistic approach of naturopathic medicine than usually indicated within the ICD$10 \mathrm{key}$. The indications are presented in the following, with the specific ICD-10 keys mentioned in brackets. 
2.1 Empiricially Proven Indications (Classified as Far as Possible According to ICD-10, WHO, Version 2013)

Endocrine, Nutritional, and Metabolic Diseases

Type II diabetes mellitus (E 11)

Obesity (E 66)

Metabolic syndrome (E 88.9)

Hyperlipidemia (E 78).

Diseases of the Cardiovascular System

Arterial hypertension (I 10)

Coronary artery disease with all associated risk factors (I 25)

Heart failure (I 50).

Diseases of the Musculoskeletal System and Connective Tissue

Rheumatoid arthritis (M 05 - M 07)

Degenerative diseases of the musculoskeletal system (M 15 - M 19)

Degenerative joint diseases, osteoarthritis (M 19.9)

Collagenosis (M 32, M 35)

Spondylarthropathia (M. Bechterew) (M 45)

Degenerative diseases of the dorsal spine (M 47.9)

Degenerative thoracic/lumbar syndrome (M 47.2)

Chronic low and upper back pain (M 54)

Acute and chronic cervical/lumbar syndrome (M 54.1)

Fibromyalgia (M 79.0).

Diseases of the Nervous System

Migraine (G 43)

Chronic tension-type headache (G 44).

Psychological Disorders

Depressive mood disorder (mild to moderate) (F 32, F 33)

Psychovegetative exhaustion, burn-out(F 43 - F 48).

Diseases of the Digestive System

Functional gastrointestinal diseases (K 30, K 58, K 59)

Irritable bowel syndrome

Inflammatory bowel disease (K 50, K 51)

Chronic constipation (K 59.0)

Fatty liver (K 70, K 76.0).

Diseases of the Respiratory System

Chronic bronchitis (J 42)

Chronic-obstructive pulmonary disease (J 40 - J 44)

Asthma (J 45)

Chronic sinusitis (J 32)

Allergic rhinitis (hay fever) (J 30)

Allergic diathesis ( $\mathrm{T}$ 78.4)

Recurring infections of the upper respiratory tract ( $\mathrm{J} 06.9)$.

\section{Diseases of the Urogenital System}

Recurring cystitis (N 30)

Dysmenorrhea and premenstrual syndrome ( 92 - N 94)

Climacteric syndrome (N 95)
Fluor genitalis (N 76)

Female and male fertility disorders (N 97, N 46).

Diseases of the Skin

Neurodermatitis (L 20)

Psoriasis (L 40)

Urticaria (L 50)

Acne (L 70).

Diseases of the Blood and the Blood-Forming Organs and Certain Disorders Involving the Immune System

Susceptibility to infections (D 80.9).

Diseases of the Eye and the Adnexa

Glaucoma (H 40).

\section{Contraindications and Safety}

\subsection{Contraindications to Fasting Therapy}

Cachexia

Anorexia nervosa and eating disorders

Uncontrolled hyperthyroidism

Advanced cerebrovascular insufficiency or dementia

Advanced liver or kidney insufficiency

Pregnancy and nursing.

\subsection{Indications Presenting a Risk and Thus Mandatory Need Guidance}

Treatment should be guided and accompanied by an experienced physician

Addictions

Type I diabetes mellitus

Psychotic disorders

Unstable or severe coronary artery disease

Retinal detachment

Ventricular and/or duodenal ulcer

Cancer and malignant disease.

Note: While long-term fasting in cancer treatment is supported only by some case reports, more research is needed. Short-term fasting is promising as adjunctive treatment during chemotherapy cycles. Fasting seems to work in synergy with chemotherapy of selected malignant tumors and reduces side effects of the main treatment. Forthcoming results from clinical trials are expected to provide concrete treatment recommendations $[52,43,44]$.

\subsection{Medications That Need to Be Adjusted During Fasting} Therapy

Non-steroidal anti-inflammatory drugs (NSAIDs) Systemic corticoids 
Antihypertensives (especially beta-blockers and diuretics)

Antidiabetics

Contraceptives (restricted effect)

Anti-coagulants

Psychotropics (especially neuroleptics and lithium)

Anticonvulsants.

\subsection{Examination before Starting and during Fasting Therapy}

Detailed patient history

Comprehensive physical examination

Basic neurological and psychological status

Complete blood count, electrolytes, liver and kidney parameters, uric acid, basal TSH (weekly tests if indicated)

Blood pressure, pulse

ECG and ultrasound, if indicated.

\subsection{Possible Reactions during Fasting Therapy}

Symptoms of slight circulatory dysregulation

Mild hypoglycemia

Electrolyte disturbances, hyponatremia

Headaches, migraine

Acute back pain

Muscle cramps

Impaired vision (temporary)

Fluid retention (temporary)

Changes in sleep patterns.

\subsection{Criteria for Discontinuing Fasting Therapy}

\section{Non-compliance}

Higher-grade cardiac arrhythmias

Stomach and reflux symptoms

Severe electrolyte disturbances

$\left(\mathrm{K}^{+}<3.0 \mathrm{mmol} / \mathrm{l}\right.$ or $\mathrm{Na}^{+}<125 \mathrm{mmol} / \mathrm{l}$ or $\left.\mathrm{Cl}<90 \mathrm{mmol} / \mathrm{l}\right)$

Circulatory depression ( $\mathrm{HF}<45 / \mathrm{min}$, RRsys $<70 \mathrm{~mm} \mathrm{Hg}$ and/or RRdia <40).

\section{Methods}

In the following, the method of fasting therapy according to Buchinger is described.

\subsection{Process Quality}

4.1.1 Preparing for Fasting - on the Day before Beginning to Fast Calorie reduction (vegetarian, $<4,200 \mathrm{~kJ}$ or $<$ approximately $1,000 \mathrm{kcal} /$ day)

Elimination of stimulants (caffeine, alcohol, nicotine)

Mild to normal physical activity
Cognitive/emotional preparation (change of habits and daily activities, more rest).

\subsubsection{Fasting Beverages - Daily Fasting Beverages during Buchinger} Fasting

0.251 fruit or vegetable juice (freshly pressed, organic)

0.25 l vegetable broth

Herbal teas, facultative with honey (maximum 2-3 teaspoons per day) Water.

These supplements deliver some limited nutritional energy intake, e.g., by carbohydrates to reduce protein catabolism [49] and micronutrients. Total fluid supply is minimum 2.51 per day.

\subsubsection{Accompanying Cleansing/Purging Procedures}

Cleansing/purging procedures at the beginning of fasting: Typically, in the morning of the first fasting day, 30-40 g of Glauber's salt (sodium sulfate) - depending on body weight - are dissolved in 11 of water and taken within $20 \mathrm{~min}$. The taste can be improved with a small amount of lemon juice.

Approximately $30 \mathrm{~min}$ after drinking Glauber's salt solution, the patient drinks further $0.5-1.01$ of tea or water, so that enough liquid is available to dissolve the nonabsorbable Glauber's salt in the intestinal lumen and to stimulate peristalsis through increasing pressure against the large intestinal walls in order to trigger bowel movements.

The Glauber's salt dosage may be reduced or another form of milder purging procedure should be considered in case of

- sensitive gastrointestinal tract (e.g., gall bladder complaints, tendency to gastritis and/or diarrhea)

- hypothension

- history of headaches

- history of acute back pain

- burn-out, exhaustion

- asthenic constitution.

Purging procedures during fasting: Cleansing/purging procedures are recommended because of

- reduced intestinal peristalsis when initiating fasting

- continous basal secretion in the digestive tract (e.g., bile) which, if not eliminated, can lead to symptoms like nausea and bloating

- continous desquamation of gastrointestinal mucosa cells and intestinal microbiota which can lead to toxic stress.

Additional cleansing/purging procedures are recommended to be carried out every other day (in individual cases every day), usually with an enema with well-tempered water or high colonics. As an alternative, 1-2 teaspoons of Epsom salt (magnesium sulfate) in 0.251 of water can be used.

\subsubsection{Boosting All Excretory Systems during Fasting}

Physical activity causes a general stimulation of the macro- and microcirculation in the body, and also in excretory organs, and can enhance their activity (see 4.1.5).

Stimulation of renal function through daily fluid intake of at least 2.51 .

Stimulation of bowel movements (see 4.1.3).

Stimulation of lung activity since gas exchange and excretion of carbonic acid is enhanced by physical activity.

Stimulation of liver function with daily application of liver packs (e.g., hot water bottle wrapped in a damp linen cloth), for approximately $30 \mathrm{~min}$ in a lying position, e.g., at noon.

Stimulation of skin function and metabolism by active or passive perspiration, e.g., through hot showers/baths, hydrotherapy, and water treatments according to Sebastian Kneipp.

Sauna, skin-brushing, hot drinks, and physical activity.

Since fasting patients tend to feel cold easily, these procedures also beneficially enhance the feeling of body warmth.

Cleansing of the buccal cavity by brushing teeth and tongue daily. 


\subsubsection{Physical Activity [50]}

Adequate individually adapted aerobic activity (with caution during the first 3 days of fasting) should take place daily for

- promoting general circulatory activity (see 4.1.4)

- preserving/increasing muscular strength

- avoiding uncontrolled protein catabolism due to immobility

- increasing respiratory acid excretion (see 4.1.4) and increased oxygen uptake through muscle cells

- promoting thermogenesis, since heat production decreases as a result of decreased resting metabolic rate and absence of diet-induced thermogenesis (fasters should dress warmly to prevent feeling cold)

- enhancing the lymphatic flow

- supporting well-being and self-esteem, promoting self-efficacy.

\subsubsection{Relaxation and Rest}

Fasting persons need enough time for rest and relaxation, self-experience and reflection, possibly spiritual practice, periods of silence, tranquility, and meditation [48]. Fasting may be a very suitable therapy to support practice and aims of mind-body medicine.

\subsubsection{Nutrition}

Fasting beverages, supplements, and food before and after fasting should be organic and fresh. During the entire fasting process, it is important to ensure a high quality of all products used.

\subsubsection{Fast-Break (Breaking the Fast) and Refeeding Period}

Fasting ends with the so-called fast-break on the last day of fasting. Typically, a ripe apple raw or cooked is eaten slowly. In the evening a potato soup is served. The 'refeeding' diet is a light lacto-vegetarian diet, rich in fiber (whole grain, prunes, possibly linseed) in accordance with individual tolerance, unsaturated fats (cold-pressed vegetable oils), and few saturated fats. Chewing is done slowly and consciously. On the first refeeding day, approximately $3,300 \mathrm{~kJ} / 800 \mathrm{kcal}$, on the second approximately 4,200 $\mathrm{kJ} / 1,000 \mathrm{kcal}$, the third approximately $5,000 \mathrm{~kJ} / 1,200 \mathrm{kcal}$, and the fourth approximately $6,700 \mathrm{~kJ} / 1,600 \mathrm{kcal}$ are taken up. Between meals patients should continue to drink plenty of fluids. Spontaneous bowel movement and defecation should occur between the first and the fourth day.

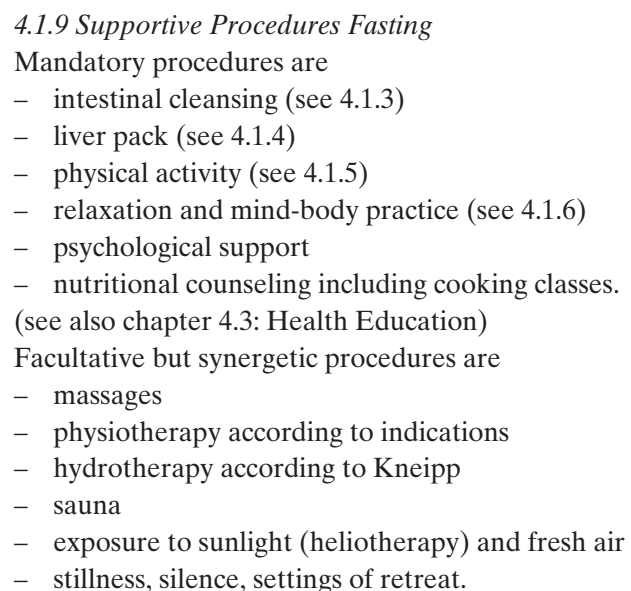

\subsubsection{Supplements}

According to the nutritional history and particularly in case of increased requirements or suboptimal status of the tissues, supplementation with natural products containing proteins, micronutrients (minerals and vitamins), and essential fatty acids can be recommended by the physician.

Protein: We do not consider a protein supplementation as indispensable since in Western countries there is an overabundance of proteins in food and the population has an adequate nutritional protein state. During fasting, controlled protein catabolism can even contribute to the therapeutic efficacy [49]. In contrast to starvation, fasting is not associated with protein-wasting but with protein-sparing energy metabolism. Importantly, protein loss is not solely the result of reduction in skeletal muscle mass but also the use of other protein sources (labile protein pool or reserve). Interestingly, protein loss is much smaller in women versus men, at least in obese subjects after 28 days of Buchinger fasting [50]. In individual cases, protein intake from natural products (buttermilk, yoghurt, other milk products or almond or soy milk) may be indicated.

Micronutrients (vitamins and minerals) and essential fatty acids: For a fasting period of 2-4 weeks, a micronutrient supplement is normally not necessary for people with a well-balanced nutritional status. If a scarce supply of certain micronutrients is suspected or if there is an increased requirement, supplements can be given. Vitamins and minerals are supplied by juices and vegetable broths. In the chronically depleted, micronutrients are supplemented and natural essential fatty acids may be given in limited amounts by cold-pressed linseed and sunflower oil.

\subsubsection{Subjective Complaints and Fasting Crises}

Adverse effects and symptoms as well as the subjective perception of a fasting crisis can occur occasionally, especially in the first 3 days.

General measures to recommend: empathic attention, self-help strategies of complementary and integrative medicine, eventually pharmacological therapy and supplements.

\subsubsection{Fasting Duration}

According to Buchinger, the optimal therapeutic fasting duration is 2-4 weeks, always taking into consideration the individual's initial condition and the evolution during fasting. Often, shorter fasting periods are better feasible or may be medically preferred, especially for underweight people. Single fasting days can be also very useful, especially repeated on the long run. Longer fasting periods (up to 6 weeks) can be helpful if indicated. The ÄGHE recommends a standard duration of 7-10 days plus 1 pre-cleansing day before and 3 refeeding days after fasting. For healthy people who do not intend to fast for therapeutic reasons, the shorter 'fasting for the healthy' has proven its worth (see chapter 5: Fasting for the Healthy).

\subsection{Medical Supervision}

\subsubsection{Patient History}

In patient history, eating disorders, psychosocial stress, and the often concealed use of medications or abusive drugs should be addressed. The patient must be given an adequate opportunity to ask questions about the goal and method of fasting therapy and must be informed about the importance of his or her own motivation.

\subsubsection{Physical Support}

In addition to the usual physical examination, constitutional characteristics should also be considered. The ÄGHE recommends considering characteristics such as 'full' (overabundance) and 'empty' (depleted; see also conceptions of traditional European and Chinese medicine) during history-taking and diagnostic investigation. Understanding the individual constitution is important for fasting therapy, especially when choosing the type/method of fasting and the supportive measures for optimizing the therapy. Patients with 'depleted constitution' tend to have a low body mass index $\left(<21 \mathrm{~kg} / \mathrm{m}^{2}\right)$, have little vitality, and are frequently tired with tendency to depressive mood and physically prominent coldness of periphery (hands/feet). The muscle tone is weak, the connective tissue is loose, the blood pressure tends to be low $(<110 \mathrm{~mm} \mathrm{Hg}$ systolic) and the heart rate slow $(<60 / \mathrm{min}$; not due to endurance exercise). Patients with constitutional aspects of 'emptiness' require tighter monitoring by the fasting physician, since it may be necessary to prescribe supportive measures in order to improve the patient's tolerance to the fasting therapy.

\subsubsection{Treatment Schedules}

A treatment schedule should not be compiled schematically, but rather with an individually designed fasting support concept. 


\subsubsection{Laboratory Diagnostics}

For every patient, the following laboratory tests must be conducted, unless recent test results from an external source are available:

- fasting blood sugar

- electrolytes

- uric acid

- liver function

- renal function

- blood count

- TSH basal.

\subsubsection{Technical Clinical Diagnostics}

To be performed before fasting:

- ECG

- Stress ECG or echocardiography

If indicated, the following examinations can be additionally performed:

- 24-h blood pressure monitoring

- echocardiography

- abdominal ultrasound

- duplex sonography of the vascular system

- bioimpedance measurement (BIA) for assessing body composition and hydration state

- sleep apnea screening.

\subsubsection{Individual Medical Monitoring}

Regular monitoring of the fasting process by a physician specialized in fasting should be performed (see 4.4.1).

\subsection{Health Education}

\subsubsection{Goal and General Framework}

The core of the educational program aims to provide physiological knowledge and to enhance self-experience as well as motivation skills The initial goal is to help people to stop unhealthy behavior patterns and thereafter, through naturopathic and integrative health education, to reduce risk factors over the long term as well as to increase quality of life and feelings of psychosocial well-being.

\subsubsection{Emotional Support}

'During fasting the body feels good, but the soul goes hungry' [10]: The rediscovery of sources of positive emotions such as art, literature, music, meditation, and nature as well as human relationships and spirituality is made easier by fasting and stabilizes the emotional balance of a person. Giving up unhealthy but formerly enjoyable daily habits is easier after a fast, since sources of pleasure outside of the nutritive sphere can be found.

\subsubsection{Nutritional Therapy}

Nutritional therapy (theory and practice) is a vital and integral component of fasting. After the fasting therapy and refeeding period, nutrition should follow the recommendations/concepts of a healthy fat-modified and freshly prepared plant-based whole-food diet, taking into consideration also individual tolerance.

\subsubsection{Physical Activity, Physiotherapy}

Physical activity (see 4.1.5) should be part of the program of every fasting person. The goal is to motivate the patient to maintain physical activity and to let him discover the joy of outdoor activities. The physical program and its intensity must be adapted to the individual condition. Gymnastics or yoga classes promote agility and coordination but cannot replace aerobic training. Every patient should be informed about the positive health aspects of physical activity.

\subsubsection{Behavioral and Lifestyle Modification}

The fasting self-experience enhances perceived self-efficacy and motivation. The goals of behavioral and lifestyle modification are to improve eating habits, to increase physical activity, and to improve stress management. Behavior modification is indispensable for practical feasibility and contains cognitive, emotional, and practical aspects. The instruction is given interactively in group sessions using established behavior modification techniques, possibly oriented toward a deeper psychological level.

Behavior modification consists of

- assessment of one's own behavior and possible relations to illness

- motivation reinforcement

- monitoring flexibility

- relapse prevention.

\subsubsection{Relaxation Therapy}

Meditation, visualization, breathing techniques, yoga, tai chi, autogenics, and progressive muscle relaxation are the most commonly taught and used methods.

\subsubsection{Scope}

Naturopathic health education is multidisciplinary and multimodal. Within the framework of inpatient fasting therapy, the following curriculum units with the following contents belong to the basic program:

Nutrition (3-4 h)

Theory of physical exercise (1-2 h)

Behavioral therapy, lifestyle modification (3-5 h)

General medical information (1-2 h)

Cultural activity and creative therapy and related items for the dietetics of the soul (5-10 h)

Psychological classes, striving for emotional balance

Practical instructions in the cooking classes (minimum $8 \mathrm{~h}$ ).

\subsection{Quality Control}

The specifications on quality control should be adapted according to the categories as outlined below

I Inpatient fasting in clinics, directed by physicians specialized in fasting

II Outpatient fasting, supervised by local physicians specialized in fasting

III Fasting for the healthy, supervised by nonmedical fasting guides.

\subsubsection{Treatment Team}

The treatment team must be self-experienced in fasting and multidisciplinary (table 1).

\subsection{Outcome Assessment and Quality Control}

A regular quality assessment should be conducted according to the requirements and regulations for inpatient treatments. Fasting therapy should be periodically monitored by outcome research. Physicians specialized or trained in fasting therapy should attend 2 ÄGHE conferences per year or similar professional training in other countries.

Follow-up assessments: Fasting offers an important impulse for inducing sustainable health-promoting lifestyle modification. The future behavioral strategy should be discussed with the patient. Here, cooperation with physicians, behavioral therapists/psychologists, fitness trainers, nutritionists, and self-help groups is necessary. The ÄGHE recommends the cooperation model between clinics, local physicians, and fasting guides. Long-term effects should be evaluated in patient samples. Repeating the fasting once per year is recommendable. 
Table 1. Treatment team for inpatient fasting therapy

\begin{tabular}{|c|c|}
\hline Qualification prerequisites for fasting treatment & Licensed training / additional qualification \\
\hline $\begin{array}{l}\text { Physician with board certification in fasting therapy (fasting } \\
\text { physician ÄGHE) }\end{array}$ & I,II, (III) \\
\hline $\begin{array}{l}\text { Physician with board certification for nutritional medicine } \\
\text { (DAEM/DGEM) }\end{array}$ & $\mathrm{I},(\mathrm{I})$ \\
\hline Nutritionist and/or dietician & $\mathrm{I}, \mathrm{II}$ \\
\hline Physiotherapist & I \\
\hline Psychologist or physician with additional expertise & I \\
\hline $\begin{array}{l}\text { Dietetically trained cook with qualification as organic and } \\
\text { vegetarian cook }\end{array}$ & I \\
\hline Licensed nurse, trained in fasting & I \\
\hline Fasting guide / supervisor & (I), II, III \\
\hline \multicolumn{2}{|c|}{$\begin{array}{l}\text { I = Inpatient fasting in clinics, monitored by fasting physicians; II = Outpatient supervised fasting, monitored by loca } \\
\text { physicians; III = Outpatient fasting, monitored by fasting supervisors. } \\
\text { ÄGHE = Medical Society for Fasting Cures and Nutrition (Ärztegesellschaft für Heilfasten und Ernährung); } \\
\text { DAEM/DGEM = German Academy / German Society for Nutritional Medicine (Deutsche Akademie / Deutsche } \\
\text { Gesellschaft für Ernährungsmedizin). }\end{array}$} \\
\hline
\end{tabular}

\section{Fasting for the Healthy}

In the first edition of his book 'Heilfasten' [2], Buchinger already emphasized the necessity of preventive fasting. 'The socalled healthy person should fast! A fast every year shall protect him from disease and infirmity!'. In 1976, the first fasting manual was published [12]. As a result, fasting for the healthy developed successfully in Germany with the help of this guidebook and support by a network of trained fasting guides.

\subsection{Definition of 'Fasting for the Healthy'}

A healthy person is one who feels well, perceives his bodily and psychological state as well and needs no medications. He/ she must be emotionally and mentally stable and capable of making personal decisions. Eating disorders and addictions (e.g., alcohol, drugs) are contraindications to fasting for the healthy. Fasting for the healthy describes short-term fasting with individual responsibility in order to promote health and is a form of adult health education.

\subsection{Goals of Fasting for the Healthy}

- New experiences of physical, emotional, and mental perception and the possibility of expanding on these

- Discovering the ability to live well without nourishment

- Positive experience of abstinence in a consume-driven society

- Fasting as a strong impulse for changing nutritional and eating habits

- Implementing self-help measures for daily life (e.g., short fasting during slight illnesses).

The ÄGHE advocates and supports cooperation models

- between fasting physicians in clinics and local physicians

- between local physicians and fasting guides trained by selected institutions
- between fasting clinics and fasting guides trained by selected institutions.

The ÄGHE sets as its goal that trained fasting guides have a fasting physician in proximity when possible, as a contact person for support and safety.

\subsection{Methodology of Fasting for the Healthy}

(See chapter 4: Methods, 4.1.1-4.1.9)

Characteristic of fasting for the healthy is, that it can be done either at home - also while working - with an adult education facility or in resort areas (hotels, boarding houses, retreat centers, or cottages). It can be done alone or in a group, then usually under the guidance of a licensed fasting supervisor. In any case, fasting is performed under one's own responsibility (even if a physician is present or nearby). For the first fasting experience, the fasting week ( 8 days: 1 pre-cleansing day, 5 fasting days, and 2 refeeding days) under trained supervision has been well established, at best within a group. The ÄGHE supports the expert supervision of fasting for the healthy by fasting guides trained in institutions that are approved by the ÄGHE.

\section{Acknowledgment}

The original guidelines conference was financially supported by the Erich Rothenfußer Foundation, Munich, Germany and the Clinic Buchinger-Wilhelmi, Überlingen, Germany.

\section{Disclosure Statement}

The authors declare that there is no conflict of interest concerning this paper. 


\section{References}

1 Wilhelmi de Toledo F: Therapeutic Fasting: The Buchinger Amplius Method. Stuttgart, Thieme, 2012.

2 Buchinger O: Das Heilfasten und seine Hilfsmethoden als biologischer Weg, ed 24. Stuttgart, Hippokrates, 2005.

3 Mayr FX: Fundamente zur Diagnostik der Verdauungskrankheiten. Bietigheim, Turm, 1921.

4 Fontana L, Patridge L, Longo V, et al.: Extending healthy live spam from yeast to humans. Science 2010;328:321-326.

5 Fahrner H: Fasten als Therapie, ed 2. Stuttgart, Hippokrates, 1991.

6 Wilhelmi de Toledo F, Buchinger A, Burggrabe H, et al.: Leitlinien zur Fastentherapie. Forsch Komplementärmed Klass Naturkeilkd 2002;9:189-198.

7 Wilhelmi de Toledo F: Fasten/Fastentherapie. Physiologie des Fastens; in Bühring M, Kemper FH, Mathiessen PF (eds): Naturheilverfahren und Unkonventionelle Medizinische Richtungen. Berlin, Springer, Loseblatt-System, 1998.

8 Wilhelmi de Toledo F, Friebe R, Hebisch D, Kuhn C, Platzer G, Schrag S: The Klinik Buchinger Programme for the treatment of obesity; in Ditschuneit H, Gries FA, Hauner H, Schusdziarra V, Wechsler JG (eds): Obesity in Europe 1993. London, John Libbey and Company Ltd., 1994, pp 289-293.

9 Buchinger A, Lindner BN: Original Buchinger Heilfasten. Stuttgart, Hüthig, 2000.

10 Kuhn C: Heilfasten. Freiburg i.Br., Herder, 1999.

11 Buchinger O: Zur Hygiene des inneren Menschen. Bad Pyrmont, Leonhard Friedrich, 1947.

12 Lützner H: Wie neugeboren durch Fasten, ed 28. München, Gräfe und Unzer, 2001.

13 Rauch E: Lehrbuch der Diagnostik und Therapie nach F.X. Mayr. Stuttgart, Hüthig, 1998.

14 Brosig V: Schrothkur. Hannover, Schlüterscher Verlag, 2001.

15 Anemueller H: Anemuellers Molkebuch. Waldthausen, Ritterhude, 2000

16 Varady KA, Hellerstein MK: Alternate-day fasting and chronic disease prevention: a review of human and animal trials. Am J Clin Nutr 2007;86:7-13.

-17 Trepanowski JF, Canale RE, Marshall KE, Kabir MM, Bloomer RJ: Impact of caloric and dietary restriction regimens on markers of health and longevity in humans and animals: a summary of available findings. Nutr J 2011;10:107.

18 Liebermeister H, Hilzensauer B, Morath D: Spätergebnisse nach Gewichtsreduktion bei Fettsüchtigen. Akt Ernähr 1989;14:143-148.

19 Security Department of Health and Social Security (DHSS): The use of very low calorie diets in obesity. Report on health and social subjects No. 31. Committee on medical aspects of food policy. Report of the working group on very low calorie diets. HMSO, 1987. http://europepmc.org/articles/PMC1711454/ pdf/jroyalcgprac00019-0003.pdf(accessed 28.11.13).

20 Wechsler JG: Aktuelle Therapie der Adipositas. Deut Med Wochenschr 1997;122:1287-1290.

21 Fontana L, Villareal DT, Weiss EP, Racette SB, Steger-May K, Klein S, Holloszy JO, Washington University School of Medicine CALERIE Group: Calorie restriction or exercise: effects on coronary heart disease risk factors. A randomized, controlled trial. Am J Physiol Endocrinol Metab 2007;293:E197-202.
22 Elia M: Effect of starvation and very low calorie diets on protein-energy interrelationships in lean and obese subjects; in Scrimshaw NS, Schürch B (eds): Proceedings of an IDECG Workshop. Waterville Valley, 1991, pp 249-284.

23 Michalsen A: Prolonged fasting as a method of mood enhancement in chronic pain syndromes: a review of clinical evidence and mechanisms. Curr Pain Headache Rep 2010;14:80-87.

24 Huether G, Zhou D, Schmidt S, Wiltfang J, Ruther E: Long-term food restriction down-regulates the density of serotonin transporters in the rat frontal cortex. Biol Psychiatry 1997;41:1174-1180.

25 Gilbert C, Blanc S, Le Maho Y, Ancel A: Energy saving processes in huddling emperor penguins: from experiments to theory. J Exp Biol 2008;211:1-8.

26 Le Maho Y: Nature and function. Nature 2002;416:21.

27 Robin JP, Frain M, Sardet C, Groscolas R, Le Maho Y: Protein and lipid utilization during long-term fasting in emperor penguins. Am J Physiol 1988;254: R61-68.

28 Müller H, Wilhelmi de Toledo F, Resch KL: Fasting followed by vegetarian diet in patients with rheumatoid arthritis: a systematic review. Scand J Rheumatol 2001;30:1-10

29 Kjeldsen-Kragh J, Haugen M, Borchgrevink CF, Laerum E, Eek M, Mowinkel P, Hovi K, Forre O: Controlled trial of fasting and one-year vegetarian diet in rheumatoid arthritis. Lancet 1991;338:899-902.

30 Li C, Ostermann T, Hardt M, Lüdtke R, BroeckerPreuss M, Dobos G, Michalsen A: Metabolic and psychological response to 7-day fasting in obese patients with and without metabolic syndrome. Forsch Komplementmed 2013;20:413-420.

31 Peper E: Evaluation der Effekte und Erfolge von stationären Heilfastenmassnahmen. Frankfurt/M, Lang, 1999.

32 Schubmann R: Therapeutisches Fasten bei Adipositas und metabolischem Syndrom. Zeitschrift für Komplementärmedizin 2009;1:14-17.

33 Ditschuneit H: Der Stoffwechsel bei Fettsucht und bei komplettem Fasten. Medizin und Ernährung 1971;12:169-177.

34 Gohler L, Hahnemann T, Michael N, Oehme P, Steglich HD, Conradi E, Grune T, Siems WG: Reduction of plasma catecholamines in humans during clinically controlled severe underfeeding. Prev Med 2000;30:95-102.

35 Schmidt S, Stange R, Lischka E, Kiehntopf M, Deufel T, Loth D, Uhlemann C: Uncontrolled clinical study of the efficacy of ambulant fasting in patients with osteoarthritis. Forsch Komplementmed 2010;17:87-94.

36 Michalsen A, Li C, Kaiser K, Lüdtke R, Meier L, Stange R, Kessler C: In-patient treatment of fibromyalgia: a controlled nonrandomized comparison of conventional medicine versus integrative medicine including fasting therapy. Evid Based Complement Alternat Med 2013;2013:908610.

37 Goldhamer A, Lisle D, Parpia B, Anderson SV, Campbell TC: Medically supervised water-only fasting in the treatment of hypertension. J Manipulative Physiol Ther 2001;24:335-339.
8 Goldhamer AC: Initial cost of care results in medically supervised water-only fasting for treating high blood pressure and diabetes. J Altern Complement Med 2002;8:696-697.

39 Müller H, Wilhelmi de Toledo F, Schuck P, Resch KL: Blutdrucksenkung durch Fasten bei adipösen und nichtadipösen Hypertonikern. Perfusion 2001; 14:108-112.

40 Michalsen A, Schneider S, Rodenbeck A, Lüdtke R, Huether G, Dobos GJ: The short-term effects of fasting on the neuroendocrine system in patients with chronic pain syndromes. Nutr Neurosci 2003; 6:11-18.

41 Lipecki R: Klinische Studie zur Effizienz einer kombinierten Heilfastenbehandlung als Migränetherapie. Inaugural Dissertation, Universität Würzburg, 1990, pp 1-53.

42 Michalsen A, Hoffmann B, Moebus S, Backer M, Langhorst J, Dobos GJ: Incorporation of fasting therapy in an integrative medicine ward: evaluation of outcome, safety, and effects on lifestyle adherence in a large prospective cohort study. J Altern Complement Med 2005;11:601-607.

43 Lee C, Longo VD: Fasting vs dietary restriction in cellular protection and cancer treatment: from model organisms to patients. Oncogene 2011;30:3305-3316.

44 Safdie FM, Dorff T, Quinn D, Fontana L, Wei M, Lee C, Cohen P, Longo VD: Fasting and cancer treatment in humans: a case series report. Aging 2009;1:988-1007.

45 Fond G, Macgregor A, Leboyer M, Michalsen A: Fasting in mood disorders: neurobiology and effectiveness. A review of the literature. Psychiatry Res 2013;209:253-258.

46 Lischka E, Lischka N: Fasten mit Obst- und Gemüsesäften. Niedernhausen, Falken, 2000.

47 Raffaghello L, Lee C, Longo V, et al.: Starvationdependent differential stress resistance protects normal but not cancer cells against high-dose chemotherapy. Proc Natl Acad Sci USA 2008;105:15-20.

48 Brantschen N: Fasting: What, Why, How. New York, Crossroad Publishing Company, 2010.

49 Wendt L: Hypoporopathie. Krankheiten verminderter Kapillarmembranpermeabilität, ed 2. Frankfurt/M, Koch, 1973.

50 Steiniger J, Schneider A, Bergmann S, Boschmann M, Janietz K: Effects of fasting and endurance training on energy metabolism and physical fitness in obese patients. Forsch Komplementmed 2009;16:383-390.

51 Liebscher D: Auswirkungen religiösen Fastens auf anthropometrische Parameter, Blutfettwerte und Hämodynamik normalgewichtiger gesunder Probanden.Dissertation. Medizinische Fakultät Carl Gustav Carus der Technischen Universität Dresden, 2012.

52 Lee C, Raffaghello L, Brandhorst S, Safdie FM, Bianchi G, Martin-Montalvo A, Pistoia V, Wei M, Hwang S, Merlino A, Emionite L, de Cabo R, Longo VD: Fasting cycles retard growth of tumors and sensitize a range of cancer cell types to chemotherapy. Sci Transl Med 2012;4:124-127. 